\title{
The Obesity Epidemic: The USA as a Cautionary Tale for the Rest of the World
}

\author{
Christopher C. Imes • Lora E. Burke
}

Published online: 13 April 2014

(C) Springer International Publishing AG 2014

\begin{abstract}
Obesity is a global epidemic and its prevalence continues to increase in many developed and developing countries. This brief review provides an update on the prevalence of obesity in the USA and globally, reviews the underlying mechanism of several comorbidities associated with obesity, and discusses the economic burden of obesity. Although the overall prevalence of obesity in the USA is not increasing, racial and ethnic minorities continue to struggle with rising obesity rates. Globally, the largest increases are being observed in the developing countries. Given the comorbidities associated with obesity and its immense economic burden, nearly every country will soon struggle with the financial and healthcare implications of the epidemic.
\end{abstract}

Keywords Obesity $\cdot$ Prevalence $\cdot$ Cardiovascular disease . Obstructive sleep apnea · Type 2 diabetes mellitus · Economic burden

\section{Introduction}

Obesity, in both the USA and globally, is at an all-time high and its prevalence continues to increase in many developed and developing countries. Obesity is associated with several major co-morbidities and thus the overall disease burden is increasing. Concomitant with this increased disease burden, we are witnessing significant increases in direct medical costs and indirect losses in productivity, which have enormous economic implications.

The purpose of this paper is to provide an update on the prevalence of obesity in the USA and globally. We also will

C. C. Imes $\cdot$ L. E. Burke $(\bowtie)$

University of Pittsburgh School of Nursing, 415 Victoria Building;

3500 Victoria Street, Pittsburgh, PA 15261, USA

e-mail: 1bu100@pitt.edu review the underlying mechanism of several co-morbidities associated with obesity, e.g., obstructive sleep apnea (OSA), cardiovascular disease (CVD), and type 2 diabetes mellitus (T2DM). Finally, we will discuss the economic burden of obesity.

\section{Obesity in the USA}

Although the rapid increase in the prevalence of obesity in the US appears to have leveled-off in recent years, it continues to be a significant public health issue with both racial and ethnic disparities $[1 \bullet, 2 \bullet, 3,4,5 \bullet]$. Based on data from the Centers for Disease Control and Prevention's National Health and Nutrition Examination Survey (NHANES), approximately $35 \%$ of US adults were obese in 2011-2012 with $33.5 \%$ of all men and $36.1 \%$ of all women having a body mass index $(\mathrm{BMI}) \geq 30 \mathrm{~kg} / \mathrm{m}^{2}[2 \bullet \bullet]$. Middle-aged adults, those between 40 and 59 years old, had significantly higher prevalence rates of obesity compared to those aged 60 years or older, and those aged between 20 and 39 years old $(39.5 \%$ vs. $35.4 \%$ and

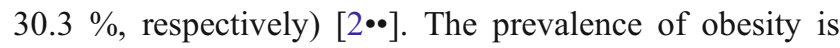
significantly higher among rural adults compared to urban adults (39.6 \% vs. $33.4 \%$ ), based on 2005-2008 NHANES data [6].

By racial and ethnic groups (see Fig. 1), Asian adults had the lowest prevalence of obesity (10.8\%), followed by nonHispanic white (32.6\%), Hispanic (42.5\%), and nonHispanic black (47.8\%) adults. Within racial and ethnic groups, there are no significant differences by sex except among non-Hispanic black adults (56.6 \% of non-Hispanic black women were obese compared to $37.1 \%$ of nonHispanic black men) [2••]. Between the periods 1999-2002 and 2007-2010, the prevalence of obesity among nonHispanic white adults has remained steady. However, during the same time span, the prevalence of obesity increased by 
Fig. 1 Obesity prevalence, by sex and race and Hispanic Origin, among adults aged 20 and over: United States, 2011-2012. Data from: Ogden CL, Carroll MD, Kit BK, Flegal KM. Prevalence of obesity among adults: United States, 2011-2012. NCHS data brief, no 131. Hyattsville, MD: National Center for Health Statistics. 2013

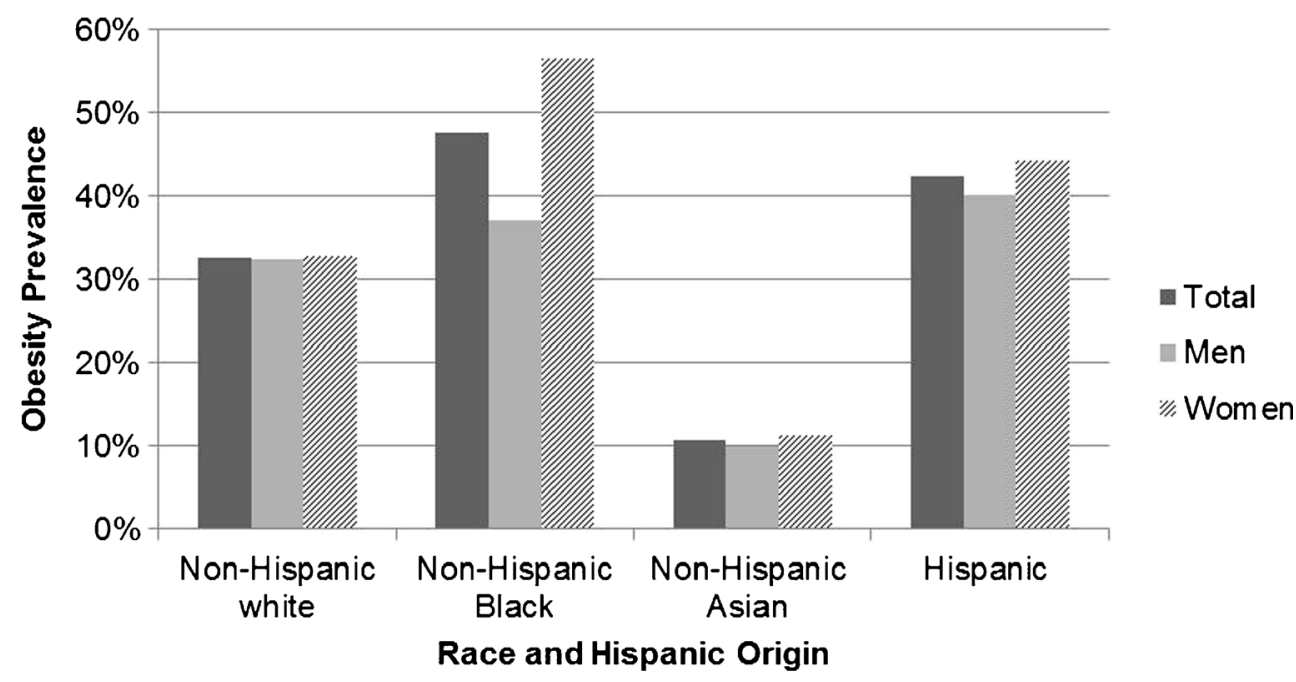

$10 \%$ among non-Hispanic black males, $6 \%$ in non-Hispanic black females, $9 \%$ in Mexican-American males, and $7 \%$ in Mexican-American females [1•].

\section{Obesity Globally}

Since 1980, the global age-standardized prevalence of obesity has nearly doubled from $6.4 \%$ (95\% uncertainty [UI] interval: $5.7-7.2 \%$ ) in 1980 to $12.0 \%$ (95\% UI: $11.5-12.5 \%$ ) in 2008 (see Fig. 2), with half the increase occurring between 2000 and 2008 [6]. Global statistics reveal that approximately 1.46 billion people had a BMI $\geq 25 \mathrm{~kg} / \mathrm{m}^{2}$ and 508 million people were obese in $2008[7 \bullet \bullet, 8]$. During that same period, the number of overweight and obese adults in the developing world tripled from 250 million in 1980 to 904 million in 2008 $[7 \bullet \bullet]$.

Using data from 105 countries and territories, Kanter and Caballero reported a greater overall prevalence of female obesity compared with male obesity [9]. The Middle East and North Africa had the greatest disparities of female overweight and obesity. However, among the developed countries, there was a greater prevalence of overweight males compared with overweight females [9].

Both rural and urban populations are affected. In several regions there is a greater increase in the prevalence of overweight and obesity in the rural areas. For example, between 1990 and 2010, the prevalence of overweight and obesity increased: in East Asia and the Pacific by $16 \%$ in rural areas compared to $8 \%$ in urban areas; and in Latin American and the Caribbean by $21 \%$ in rural areas compared to $17 \%$ in

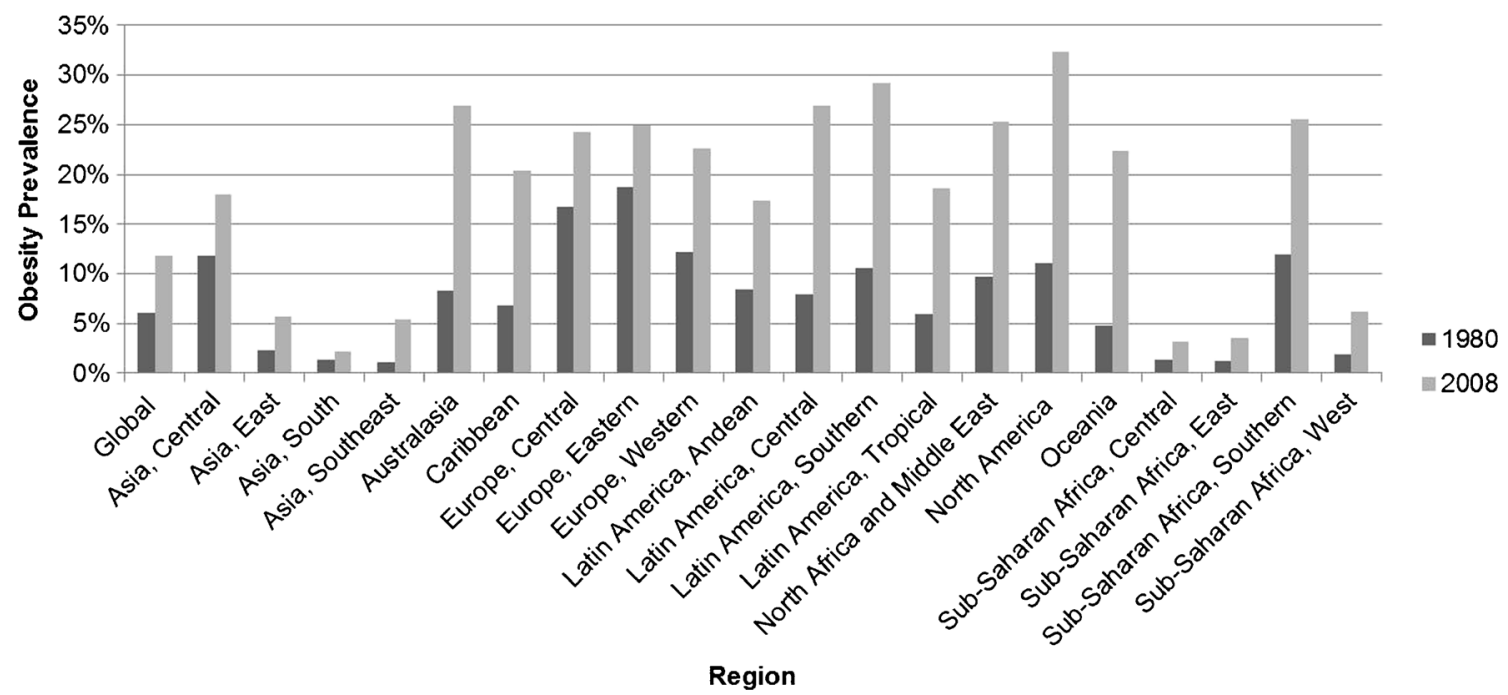

Fig. 2 Obesity prevalence by region among adults aged 20 and over, 1980 and 2008. Data from: Stevens GA, Singh GM, Lu Y, Danaei G, Lin JK, Finucane MM, Bahalim AN, McIntire RK, Gutierrez HR, Cowan M, Paciorek CJ, Farzadfar F, Riley L, Ezzati M. Global Burden of Metabolic

Risk Factors of Chronic Diseases Collaborating Group (Body Mass Index). National, regional, and global trends in adult overweight and obesity prevalences. Popul Health Metr. 2012 doi: 10.1186/1478-795410-22 
urban areas. However, taken globally the prevalence of overweight and obesity is higher in urban settings, except for in Europe and Central Asia where the prevalence is similar (approximately $41 \%$ ) in both urban and rural settings [10].

\section{Major Comorbidities Related to Obesity}

Obesity is associated with an increased incidence of serious disorders such as OSA, CVD, and type T2DM [11•, 12]. The role of obesity in these diseases is briefly reviewed. Obesity is also associated with several other co-morbid conditions (Table 1), e.g., gastrointestinal reflux, pancreatitis, polycystic ovary syndrome, some cancers, gallbladder disease, osteoarthritis, gout, chronic back pain, and psychosocial issues such as depression, social and employment discrimination, and reduced quality of life $[12,13]$.

Obstructive Sleep Apnea Obesity is a major risk factor for OSA $[11 \bullet, 12,13]$. In OSA, the upper airway, which is normally patent during sleep, collapses resulting in the complete or partial restriction of airflow resulting in apnea, hypopnea and sleep fragmentation. Obesity causes narrowing of the pharyngeal airway due to excessive soft tissue within and surrounding the airway. Additionally, lung volume can be reduced due to increased abdominal fat mass. A recumbent posture further decreases lung volumes and pharyngeal wall tension. OSA is independently associated with cardiovascular

Table 1 Main comorbidities associated with obesity

\begin{tabular}{|c|c|}
\hline System & Comorbidity \\
\hline Gastrointestinal & $\begin{array}{l}\text { Pancreatitis } \\
\text { Liver disease } \\
\text { Colon, pancreatic, gallbladder, \& esophageal } \\
\text { cancer }\end{array}$ \\
\hline Endocrine/reproductive & $\begin{array}{l}\text { Metabolic syndrome } \\
\text { Type } 2 \text { diabetes mellitus } \\
\text { Polycystic ovary syndrome } \\
\text { Breast, uterine, \& cervical cancer }\end{array}$ \\
\hline Cardiovascular & $\begin{array}{l}\text { Coronary heart disease } \\
\text { Hypertension } \\
\text { Cerebrovascular and thromboembolic disease }\end{array}$ \\
\hline Respiratory & $\begin{array}{l}\text { Obstructive sleep apnea } \\
\text { Obesity-hypoventilation syndrome } \\
\text { (Pickwickian syndrome) }\end{array}$ \\
\hline Musculoskeletal & Immobility \\
\hline Genitourinary & $\begin{array}{l}\text { Urinary stress incontinence } \\
\text { Prostate and renal cancer }\end{array}$ \\
\hline Neurological & $\begin{array}{l}\text { Idiopathic intracranial hypertension } \\
\text { Stroke }\end{array}$ \\
\hline
\end{tabular}

Adapted from: Warziski MT, Choo J, Novak J, Burke LE. Obesity. In: Moser DK, Riegel B, editors. Cardiac nursing. A companion to Braunwald's heart disease. Saunders; 2008. pp 446-462 events, heart failure, insulin resistance, and T2DM and may increase the risk for arrhythmias [14].

Cardiovascular Disease Obesity is associated with coronary heart disease; stroke; ventricular dysfunction; heart failure; and CVD mortality $[12,14]$. Fat cells, or adipocytes, function as an endocrine organ and produce various adipocytokines. These adipocytokines have an effect on lipid metabolism; inflammation; atherosclerosis; insulin resistance; immune response; vascular homeostasis; angiogenesis; and food intake [15]. Adipocytokines include tumor necrosis factor- $\alpha$ (TNF- $\alpha$ ); interleukin-6 (IL-6); plasminogen activator inhibitor-1 (PAI1); resistin; lipoprotein lipase; cholesterylester transfer protein; leptin; C-reactive protein (CRP); and angiotensinogen [15-18]. In obesity, the serum concentration of most adipocytokines is increased, most notably the proinflammatory adipocytokines.

The process of atherosclerosis begins early in life, as early as 5 years of age, when low-density lipoprotein cholesterol (LDL-C) and very low-density lipoprotein cholesterol (VLDL-C) are infiltrated and entrapped in the intima layer of large arteries and modified by enzymes into proinflammatory particles $[16,19]$. An inflammatory response occurs, causing endothelial cells to express cellular adhesion molecules while monocytes enter into the intima layer [19]. The monocytes mature into macrophages and are transformed into foam cells, also known as fatty streaks [16, 19]. Over time, the lipid-filled fatty streaks increase in size and combine into pools and grow until they occupy up to $70 \%$ of the arterial wall volume. Next, a fibrous cap develops between the endothelium and the lipid-rich core. The final stage of atherosclerosis is complex lesion development. The fibrous cap can become thin and weak due to enzymatic activity. This is a vulnerable plaque. If this lesion ruptures or fractures, a thrombus that extends into the lumen will develop, potentially occluding blood flow $[19,20]$. Obesity accelerates the atherosclerosis process due to adipocytokines that increase insulin resistance and endothelial dysfunction, inflammation, and lipid production [15-17].

Obesity is an independent risk factor for stroke. Each 1-unit increase in BMI is associated with a $4 \%$ increase in ischemic stroke risk and a $6 \%$ increase in hemorrhagic stroke risk [16-18]. The mechanism by which obesity independently increases stroke risk is not known [17]. However, the process may be mediated by prothrombotic and proinflammatory adipocytokines such as PAI1 and CRP [15, 17].

In obesity, total blood volume and cardiac output is increased in order to meet the increased metabolic demands caused by excess body weight. The increased cardiac output is achieved through increased stroke volume. In overweight and obese individuals, the left ventricular chamber dilates, resulting in increased ventricular wall stress which may increase myocardial mass leading to left ventricular 
hypertrophy. Additionally, the increased blood volume and left ventricular hypertrophy causes left atrial enlargement. These abnormalities increase the risk for heart failure and ventricular arrhythmias [16-18].

Hypertension is more frequent in obese individuals, compared to individuals with a normal weight, and as BMI increases there is a corresponding increase in the prevalence of hypertension [21]. Larger increases in blood pressure are seen in individuals with abdominal obesity [16]. Blood pressure is the result of an individual's cardiac output, which is increased in obesity, and systemic vascular resistance $[16,17]$. Due to the increased cross-sectional area of the vascular bed of adipocytes, systemic vascular resistance should be lower in obese individuals [17]. However, systemic vascular resistance is often normal or elevated. This, along with increased blood volume, causes hypertension. Once again, the inflammation, insulin resistance, and endothelial dysfunction caused by adipocytokines are factors that increase systemic vascular resistance $[16,17]$.

Type 2 Diabetes Mellitus The prevalence of T2DM increases with increased BMI [22]. In T2DM, there is reduced insulin sensitivity in peripheral tissues with a subsequent impaired function of pancreatic $\beta$-cells $[22,23]$. Adipocytokines that are increased in obesity and result in insulin resistance include: IL-6; TNF- $\alpha$; CRP; insulin-like growth factor-1; resistin; apelin; and visfatin. Serum levels of adiponection, which sensitizes peripheral tissues to insulin and inhibits $\mathrm{TNF}-\alpha$, is reduced in obesity $[15,22-24]$.

Visceral and subcutaneous adipose tissue and fat within the liver and muscles contribute to insulin resistance. Overall, the accumulation of visceral fat and insulin resistance results in higher plasma free fatty acid levels. In insulin resistance, the reduction of free fatty acid release from adipocytes by insulin through lipolysis is impaired [22, 24]. This chronically elevated level of plasma free fatty acids contributes to several inflammatory pathways that further induce insulin resistance [24].

T2DM is a leading risk factor for several conditions, e.g., kidney disease and neuropathy. Moreover, CVD is the leading cause of death among individuals with diabetes. The rising prevalence of T2DM is associated with the obesity epidemic and thus poses a serious threat to the health of those who are obese.

The Obesity Paradox Many studies have shown an obesity paradox, namely the reduced morbidity and mortality in overweight and obese individuals compared to normal weight individuals. Uretsky and colleagues found that over a mean follow-up of 2.7 years, occurrence of death, nonfatal myocardial infarction, or nonfatal stroke was lower in overweight and obese individuals compared to individuals with a normal weight (hazard ratios [HRs] from $0.68-0.77$ with normal weight being the reference groups) [25]. In a meta-analysis of 9 observational heart failure studies, Oreopoulos and colleagues found that over a mean follow-up of 2.7 years, allcause mortality was lower in overweight and obese individuals with heart failure compared to heart failure individuals with a normal weight (relative risk $[R R]=0.84,95 \%$ confidence interval $[95 \% \mathrm{CI}]: 0.79-0.90$ and $\mathrm{RR}=0.67,95 \% \mathrm{CI}$ : $0.62-0.73$ for overweight and obesity, respectively) [26]. Finally, Romero-Corral and colleagues found, in a systematic review of 40 cohort studies with 250,152 subjects and a mean follow-up of 3.8 years, that overweight individuals (BMI 2529.9) had a lower risk for total mortality ( $\mathrm{RR}=0.87,95 \% \mathrm{CI}$ : 0.81-0.94); compared to individuals with normal weight; and individuals with class I obesity (BMI 30-35) had a similar risk for total mortality ( $R R=0.93,95 \%$ CI: $0.85-1.03$ ), compared to individual with normal weight [27].

All of these reported studies examined short term risk. Reviewing only studies with 10 or more years of follow-up, Kramer and colleagues found that metabolically healthy obese individuals had an increased risk for all-cause mortality and cardiovascular events, compared with metabolically healthy individuals with a normal weight $(\mathrm{RR}=1.24$; $95 \% \mathrm{CI}$ : 1.021.55) [28 ]. Their findings show the long-term negative effects of obesity versus the short-term effects examined in the other studies.

Multi-Generational Impact A recent study suggests a multi-generational impact of obesity between mothers and their offspring. Compared to the offspring of mothers with normal BMI, the offspring of mothers who were obese early in their pregnancy had an increased all-cause mortality ( $\mathrm{HR}=1.35,95 \% \mathrm{CI}$ : 1.17 1.55) after adjustment for maternal age at delivery, socioeconomic status, sex of offspring, current age, birth weight, gestation at delivery, and gestation at measurement of BMI. Additionally, compared with offspring of mothers with normal BMI, the offspring of obese mothers had an increased risk of cardiovascular related hospital admissions ( $\mathrm{HR}=1.29,95 \% \mathrm{CI} ; 1.06-1.57)$ [29].

\section{Economic Burden of Obesity}

Due to the marked increase in obesity over the last 30 years and the increased disease burden from CVD, T2DM, and cancers associated with obesity, the economic burden of obesity in the USA and worldwide is enormous. Obesity is associated with higher healthcare costs, reduced longevity, and fewer disability-free lifeyears. Obese individuals generally report a lower quality of life and are less productive than individuals with a normal weight $[30,31 \bullet]$. 
Direct Costs of Obesity In the USA, the cost of obesity is immense. Obese individuals pay, on average, $42 \%$ more for overall healthcare costs and spend $80 \%$ more on prescription drugs [32]. Tsai and colleagues found a $9.9 \%$ and $42.7 \%$ greater per capita cost for overweight and obese individuals, respectively, compared to individuals with a normal weight [33]. Another study reported a $10 \%$ greater per capita cost for overweight individuals compared to normal-weight individuals; the per capita cost was greater by $23 \%$ for individuals with class I obesity, $45 \%$ for those with class II obesity, and $81 \%$ for those with class III obesity [34]. It was estimated that in 2008, US $\$ 147$ billion in healthcare was attributable to obesity, accounting for $9.1 \%$ of all US health expenditures [32]. However, it has been estimated that by 2030 , if the current prevalence of obesity continues, total healthcare costs attributable to obesity could be from US $\$ 861$ billion to US $\$ 957$ billion or $16 \%$ to $18 \%$ of US health expenditures [35]. The amount of health expenditures attributable to obesity in other countries is significantly lower at $2 \%$ to $5 \%$ depending on the country and source of data [30].

Indirect Costs of Obesity The indirect costs of obesity include absenteeism, the time absent from work because of illness, disability, short- and long-term absence from the labor market due to a physical or mental incapability to meet occupational demands, and premature mortality [30]. Regardless of occupation, overweight and obese employees use more sick leave and have higher sick leave attributable costs compared to their colleagues with a normal weight $[30,31 \bullet]$. Disability costs rise when illness-related long-term absence results in losses in productivity or disability payments from insurance companies and/or the government $[36,37]$. Obese individuals are at a higher risk for work disability compared to normal-weight individuals $[30,31 \cdot, 38]$. Lost productivity costs due to early death from obesity in 2007 were estimated to be over US $\$ 30$ billion in the USA [36].

\section{Conclusion}

Although the prevalence of obesity may have reached a plateau in the USA, globally, the prevalence of obesity continues to increase, especially in developing countries. An increase in obesity is accompanied by increases in CVD, T2DM, and cancers. These diseases have major economic implications for both the cost of treatment and the associated loss of productivity. Developing countries with insufficient healthcare infrastructure and finances may find themselves challenged in managing the obesity-associated comorbidities. Furthermore, the developed countries, including the USA, must plan for the enormous economic implications of obesity that will continue until we can impact the epidemiclike prevalence of overweight and obesity.
The worldwide effort to reduce obesity must be twofold: weight reduction in those individuals who are currently overweight and obese; and the prevention of overweight and obesity in children, adolescents and adults. Weight reduction among obese and overweight individuals is challenging. Studies in the USA have shown that the majority of people who lose a significant amount of weight are unable to maintain their weight loss [39-42]. However, a sustained weight loss of between $3 \%$ and $5 \%$ can result in clinically significant reductions in triglycerides and blood glucose, which can help decrease the risk for developing diabetes [43-45]. As for obesity prevention in developed countries like the USA, both national and local policies must focus on nutrition and dietary guidance and the promotion of physical activity [46]. In developing countries, the rapidly changing diet and shifting physical activity pattern are the main contributors to the increased prevalence of overweight and obesity [47, 48]. In these countries, educational campaigns may be the only foreseeable means to address the growing obesity prevalence, given the limited resources of their government and healthcare resources [48]. Nonetheless, continued efforts must be made on both fronts to address the global obesity epidemic.

Funding sources Grant T32NR009759 from the National Institute for Nursing Research of the National Institutes of Health.

\section{Compliance with Ethics Guidelines}

Conflict of Interest CC Imes declares no conflicts of interest. LE Burke declares no conflicts of interest.

Human and Animal Rights and Informed Consent This article does not contain any studies with human or animal subjects performed by any of the authors.

\section{References}

Papers of particular interest, published recently, have been highlighted as:

- Of importance

•. Of major importance

1. Centers for Disease Control and Prevention. Obesity - United States, 1999-2010. MMWR. 2013;62 Suppl 3:120-8. This supplement from Centers for Disease Control and Prevention uses data from the National Health and Nutrition Examination Survey (NHANES) between 1999 and 2011 to assess the disparities and trends over time in obesity prevalence among adults $\geq 18$ years.

2.• Ogden CL, Carroll MD, Kit BK, Flegal KM. Prevalence of obesity among adults: United States, 2011-2012. NCHS data brief, no 131. Hyattsville, MD: National Center for Health Statistics; 2013. This National Center for Health Statistics Data Brief provides the most recent statistics, from the 2011-2012 NHANES, on the prevalence of obesity in the US. 
3. Ogden CL, Carroll MD, Kit BK, Flegal KM. Prevalence of obesity in the United States, 2009- 2010. NCHS data brief, no 82. Hyattsville, MD: National Center for Health Statistics; 2012.

4. Flegal KM, Carroll MD, Kit BK, Ogden CL. Prevalence of obesity and trends in the distribution of body mass index among US adults, 1999-2010. JAMA. 2012;307:491-7.

5. Go AS, Mozaffarian D, Roger VL, Benjamin EJ, Berry JD, Blaha MJ, et al. Heart disease and stroke statistics - 2014 update: a report from the American Heart Association. Circulation. 2014. doi:10. 1161/01.cir.0000441139.02102.80. This report by the American Heart Association provided the most recent statistics on heart disease, stroke, and heart factors included obesity.

6. Befort CA, Nazir N, Perri MG. Prevalence of obesity among adults from rural and urban area of the United States: finding from NHANES (2005-2008). J Rural Health. 2012. doi:10.1111/j.17480361.2012.00411.x.

7.• Stevens GA, Singh GM, Lu Y, Danaei G, Lin JK, Finucane MM, et al. National, regional, and global trends in adult overweight and obesity prevalences. Popul Health Metrics. 2012. doi:10.1186/ 1478-7954-10-22. In this articles, the authors estimated trends between 1980 and 2008 in overweight and obesity prevalence and their uncertainty for adults 20 years of age and older in 199 countries and territories. The authors provided additional, openaccess data files with the prevalence of male and female overweight and obesity, adults $\geq 20$ years, by country and year, 1980-2008.

8. Finucane MM, Stevens GA, Cowan MJ, Danaei G, Lin JK, Paciorek CJ, et al. National, regional, and global trends in bodymass index since 1980: systematic analysis of health examination surveys and epidemiological studies with 960 country-years and 9.1 million participants. Lancet. 2011. doi:10.1016/S01406736(10)62037-5.

9. Kanter R, Caballero B. Global gender disparities in obesity: a review. Adv Nutr. 2010. doi:10.3945/an.112.002063.

10. Popkin BM, Slining MM. New dynamics in global obesity facing low- and middle-income countries. Obes Rev. 2013. doi:10.1111/ obr.12102.

11. Jensen MD, Ryan DH, Apovian CM, Ard JD, Comuzzie AG, Donato KA, et al. 2013 AHA/ACC/TOS guideline for the management of overweight and obesity in adults: a report of the American College of Cardiology/American Heart Association Task Force on Practice Guidelines and The Obesity Society. Circulation. 2013. doi:10.1161/01.cir.0000437739.71477.ee. This article contains the evidence-based update for the management of overweight and obesity in adults. Additionally, the authors provide a treatment algorithm using a primary care model for disease management of overweight and obesity patients.

12. Guh DP, Zhang W, Bansback N, Amarsi Z, Birmingham CL, Anis $\mathrm{AH}$. The incidence of co-morbidities related to obesity and overweight: a systematic review and meta-analysis. BMC Public Health. 2009. doi:10.1186/1471-2458-9-88.

13. Warziski MT, Choo J, Novak J, Burke LE. Obesity. In: Moser DK, Riegel B, editors. Cardiac nursing. A companion to Braunwald's heart disease. Saunders; 2008. pp. 446-62.

14. Drager LF, Togeiro SM, Polotsky VY, Lorenzi-Filho G. Obstructive sleep apnea: a cardiometabolic risk in obesity and the metabolic syndrome. J Am Coll Cardiol. 2013. doi:10.1016/j.jacc.2013.05.045.

15. Ronti T, Lupattelli G, Mannarino E. The endocrine function of adipose tissue: an update. Clin Endocrinol (Oxf). 2006. doi:10. 1111/j.1365-2265.2006.02474.x.

16. Poirier P, Giles TD, Bray GA, Hong Y, Stern JS, Pi-Sunyer FX, et al. Obesity and cardiovascular disease: pathophysiology, evaluation, and effect of weight loss: an update of the 1997 American Heart Association Scientific Statement on Obesity and Heart Disease from the Obesity Committee of the Council on Nutrition, Physical Activity, and Metabolism. Circulation. 2006. doi:10.1161/ CIRCULATIONAHA.106.171016.
17. Mathew B, Francis L, Kayalar A, Cone J. Obesity: effects on cardiovascular disease and its diagnosis. J Am Board Fam Med. 2008. doi:10.3122/jabfm.2008.06.080080.

18. Lavie CJ, Milani RV, Ventura HO. Obesity and cardiovascular disease: risk factor, paradox, and impact of weight loss. J Am Coll Cardiol. 2009. doi:10.1016/j.jacc.2008.12.068.

19. Imes CC, Austin MA. Low-density lipoprotein cholesterol, apolipoprotein $\mathrm{B}$, and risk of coronary heart disease: from familial hyperlipidemia to genomics. Biol Res Nurs. 2013. doi:10.1177/ 1099800412436967.

20. Libby P, Ridker PM, Hansson GK. Progress and challenges in translating the biology of atherosclerosis. Nature. 2011. doi:10. 1038/nature10146.

21. Brown CD, Higgins M, Donato KA, Rohde FC, Garrison R, Obarzanek E, et al. Body mass index and the prevalence of hypertension and dyslipidemia. Obes Res. 2000;8:605-19.

22. Yaturu S. Obesity and type 2 diabetes. J Diabetes Mellitus. 2011. doi:10.4236/jdm.2011.14012.

23. Kahn SE, Hull RL, Utzschneider KM. Mechanisms linking obesity to insulin resistance and type 2 diabetes. Nature. 2006. doi:10.1038/ nature05482.

24. Kashyap SR, Defronzo. The insulin resistance syndrome: physiological considerations. Diab Vasc Dis Res. 2007. doi:10.3132/dvdr. 2007.00

25. Uretsky S, Messerli FH, Bangalore S, Champion A, Cooper-Dehoff $\mathrm{RM}$, Zhou Q, et al. Obesity paradox in patients with hypertension and coronary artery disease. Am J Med. 2007. doi:10.1016/j. amjmed.2007.05.011.

26. Oreopoulos A, Padwal R, Kalantar-Zadeh K, Fonarow GC, Norris $\mathrm{CM}$, McAlister FA. Body mass index and mortality in heart failure: a meta-analysis. Am Heart J. doi:10.1016/j.ahj.2008.02.014.

27. Romero-Corral A, Montori VM, Somers VK, Korinek J, Thomas RJ, Allison TG, et al. Association of bodyweight with total mortality and with cardiovascular events in coronary artery disease: a systematic review of cohort studies. Lancet. 2006. doi:10.1016/ S0140-6736(06)69251-9.

28. Kramer CK, Zinman B, Retnakaran R. Are metabolically healthy overweight and obesity benign conditions?: A systematic review and meta-analysis. Ann Intern Med. 2013. doi:10.7326/0003-4819159-11-201312030-00008. This systematic review and metaanalysis of only studies with 10 or more years of follow-up found that obese individuals are at increased risk for adverse long-term outcomes, even in the absence of metabolic abnormalities, compared to metabolically healthy normal-weight individuals. This refutes several studies that reported an "obesity paradox".

29. Reynolds RM, Allan KM, Raja EA, Bhattacharya S, McNeill G, Hannaford PC, et al. Maternal obesity during pregnancy and premature mortality from cardiovascular event in adult offspring: follow-up of 1323275 person years. BMJ. 2013. doi:10.1136/ bmj.f4539.

30. Lehnert T, Sonntag D, Konnopka A, Riedel-Heller S, König HH. Economic costs of overweight and obesity. Best Pract Res Clin Endocrinol Metab. 2013. doi:10.1016/j.beem.2013.01.002.

31. Wang YC, McPherson K, Marsh T, Gortmaker SL, Brown M. Health and economic burden of the projected obesity trends in the USA and the UK. Lancet. 2011. doi:10.1016/S0140-6736(11) 60814-3. The authors used a simulation model of a continued rise in obesity in the USA and the UK to project the probable health and economic consequences over the next two decades.

32. Finkelstein EA, Trogdon JG, Cohen JW, Dietz W. Annual medical spending attributable to obesity: payer-and service-specific estimates. Health Aff (Millwood). 2009. doi:10.1377/hlthaff.28.5. w822.

33. Tsai AG, Williamson DF, Glick HA. Direct medical cost of overweight and obesity in the USA: a quantitative systematic review. Obes Rev. 2011. doi:10.1111/j.1467-789X.2009.00708.x. 
34. Arterburn DE, Maciejewski MI, Tsevat J. Impact of morbid obesity on medical expenditures in adults. Int $\mathrm{J}$ Obes (Lond). 2005;29:334-9.

35. Wang Y, Beydoun MA, Liang L, Caballero B, Kumanyika SK. Will all Americans become overweight or obese? Estimating the progression and cost of the US obesity epidemic. Obesity (Silver Spring). 2008; 16:2323-30.

36. Trogdon JG, Finkelstein EA, Hylands T, Dellea PS, Kamal-Bahl SJ. Indirect costs of obesity: a review of the current literature. Obes Rev. doi:10.1111/j.1467-789X.2008.00472.x.

37. Neovius K, Johansson K, Rossner S, Neovius M. Disability pension, employment and obesity status: a systematic review. Obes Rev. doi:10.1111/j.1467-789X.2008.00502.x.

38. Claessen H, Arndt V, Drath C, Brenner H. Overweight, obesity and risk of work disability: a cohort study of construction workers in Germany. Occup Environ Med. 2009. doi:10.1136/oem.2008. 042440.

39. Barnes AS, Kimbro RT. Descriptive study of educated African American women successful at weight-loss maintenance through lifestyle changes. J Gen Intern Med. 2012. doi:10.1007/s11606012-2060-2.

40. Butryn ML, Webb V, Wadden TA. Behavioral treatment of obesity. Psychiatr Clin N Am. 2011. doi:10.1016/j.psc.2011.08.006.

41. Kraschnewski JL, Boan J, Esposito J, Sherwood NE, Lehman EB, Kephart DK, et al. Long-term weight loss maintenance in the United States. Int J Obes. 2010. doi:10.1038/ijo.2010.94.
42. Jensen MD, Ryan DH, Apovian CM, Loria CM, Ard JD, Millen BE, et al. 2013 AHA/ACC/TOS Guideline for the Management of Overweight and Obesity in Adults: a report of the American College of Cardiology/American Heart Association Task Force on Practice Guidelines and the Obesity Society. J Am Coll Cardiol. 2013. doi:10.1016/j.jacc.2013.11.004.

43. Knowler WC, Barrett-Connor E, Fowler SE, Hamman RF, Lachin $\mathrm{JM}$, Walker EA, et al. Reduction in the incidence of type 2 diabetes with lifestyle intervention or metformin. N Engl J Med. 2002. doi: 10.1056/NEJMoa012512.

44. Milsom VA, Malcolm RJ, Johnson GC, Pechon SM, Gray KM, Miller-Kovach K, et al. Changes in cardiovascular risk factors with participation in a 12-week weight loss trial using a commercial format. Eat Behav. 2013. doi:10.1016/j.eatbeh.2013.10.004.

45. Wing RR, Lang W, Wadden TA, Safford M, Knowler WC, Bertoni AG, et al. Benefits of modest weight loss in improving cardiovascular risk factors in overweight and obese individuals with type 2 diabetes. Diabetes Care. 2011. doi:10.2337/dc10-2415.

46. Weintraub WS, Daniels SR, Burke LE, Franklin BA, Goff Jr DC, Hayman LL, et al. Value of primordial and primary prevention for cardiovascular disease: a policy statement from the American Heart Association. Circulation. 2011. doi:10.1161/CIR.0b013e3182285a81.

47. Popkin BM. Using research on the obesity pandemic as a guide to a unified vision of nutrition. Public Health Nutr. 2005;8:724-9.

48. Prentice AM. The emerging epidemic of obesity in developing countries. Int J Epidemiol. 2006. doi:10.1093/ije/dyi272. 